BULLETIN Bulletin hispanique

HispaniQuE Université Michel de Montaigne Bordeaux

119-1 | 2017

Autorité et pouvoir dans le théâtre du Siècle d'Or

\title{
Un entremés para la corte virreinal limeña
}

anotación e interpretación de una pieza de teatro breve de Peralta Barnuevo

José A. Rodríguez Garrido

\section{CpenEdition}

1 Journals

Edición electrónica

URL: http://journals.openedition.org/bulletinhispanique/4901

DOI: 10.4000/bulletinhispanique.4901

ISBN: 979-10-300-0142-6

ISSN: 1775-3821

Editor

Presses universitaires de Bordeaux

Edición impresa

Fecha de publicación: 15 junio 2017

Paginación: 245-258

ISBN: 979-10-300-0141-9

ISSN: 0007-4640

\section{Referencia electrónica}

José A. Rodríguez Garrido, « Un entremés para la corte virreinal limeña », Bulletin hispanique [En línea], 119-1 | 2017, Publicado el 15 junio 2020, consultado el 14 septiembre 2020. URL : http:// journals.openedition.org/bulletinhispanique/4901; DOI : https://doi.org/10.4000/bulletinhispanique. 4901 


\title{
Un entremés para la corte virreinal limeña: anotación e interpretación de una pieza de teatro breve de Peralta Barnuevo ${ }^{1}$
}

\author{
José A. Rodríguez Garrido \\ Pontificia Universidad Católica del Perú
}

Grâce à un travail pertinent d'annotation et d'interprétation philologique, il est possible de reconstruire et de révéler la perspective criolla que Pedro de Peralta Barnuevo a développée dans l'entremés qui devait s'intercaler entre les actes de $\mathrm{La}$ Rodoguna (1727), une œuvre destinée à célébrer l'anniversaire du roi Philippe V dans le palais vice-royal de Lima.

Mots-clés: théâtre de cour, Vice-Royauté du Pérou, culture coloniale hispanoaméricaine, entremés, annotation de textes.

Mediante una adecuada labor de anotación e interpretación filológica es posible reconstruir y revelar la perspectiva criolla que Pedro de Peralta Barnuevo desarrolló en el entremés escrito para intercalarse entre las jornadas de La Rodoguna (1727), una obra destinada a festejar los años del rey Felipe $\mathrm{V}$ en el palacio virreinal de Lima.

Palabras claves: teatro cortesano, teatro en el Virreinato del Perú, entremés, cultura criolla, anotación de textos.

Through careful annotation and philological interpretation, it is possible to reconstruct and reveal the creole perspective developed by Pedro de Peralta Barnuevo in the entremés to be performed between the acts of "La Rodoguna" (1727), a work intended for celebrating king Philip V's anniversary at the viceroyal palace of Lima.

Keywords: court theatre, Vice Royalty in Perù, Spanish American colonial culture, entremés, text annotation.

1. Este artículo se inserta en el marco del proyecto de investigación FFI2014-52007-P, «Autoridad y poder en el teatro del Siglo de Oro. Estrategias, géneros, imágenes en la primera globalización", financiado por el Ministerio de Economía y Competitividad del Gobierno de España.

Bulletin Hispanique, Tome 119, n 1 - juin 2017 - p. 245-258. 
Tres festejos teatrales componen la breve, pero significativa producción 1 dramática de Pedro de Peralta Barnuevo (Lima 1663-1743), el destacado escritor criollo, cuya actividad en los géneros más diversos (el teatro, la poesía, el discurso científico, el panegírico político, la relación festiva...) dominó la escena intelectual en la Lima virreinal durante las primeras décadas del siglo XVIII. Toda su obra dramática estuvo destinada a la escena virreinal palaciega y asociada a la celebración de acontecimientos de carácter político: Triunfos de amor y poder en 1711, para celebrar el triunfo de Felipe V en la batalla de Villaviciosa, que sella el final de la Guerra de Sucesión española; en 1720, Afectos de amor y fineza, en agasajo por el día de los años del virrey Diego Morcillo Rubio de Auñón; finalmente, en 1727, La Rodoguna, para los festejos por el día de los años del rey Felipe V) ${ }^{2}$. Para cada una de estas ocasiones, Peralta escribió no solo la comedia, sino también invariablemente la loa y algunas de las otras piezas menores, las de carácter cómico, destinadas a servir de intermedio o final de la obra principal. De este modo, la producción dramática de Peralta, a pesar del reducido número de obras, abarca una diversidad de géneros y estilos que van de la modalidad más próxima a la tragedia, en un drama como $L a$ Rodoguna, a la comicidad de carácter más popular propia de las piezas cortas.

El teatro de Peralta no ha dejado de suscitar revisiones y comentarios, aunque más de carácter general en antologías e historias del teatro hispanoamericano que a través de estudios más especializados. Particularmente las piezas cómicas breves que el propio Peralta escribió para intercalar entre sus comedias han llamado la atención por la referencia a algunas costumbres y referentes locales de su entorno, así como por la aparición de algunos vocablos o acepciones americanas $^{3}$. No obstante, estas aproximaciones se han detenido, por lo general, en la mera comprobación de este hecho, sin profundizar filológicamente en el asunto ni medir el alcance que esto implicaba en la dramaturgia de Peralta o en el proyecto literario y político del escritor.

2. La fecha que atribuyo a la representación de La Rodoguna es la que establezco en mi artículo "El teatro admirable de Lima": la fecha de composición de La Rodoguna de Pedro de Peralta y su significado político», en J. Pascual Buxó (ed.), Reflexión y espectáculo en la América virreinal, México D.F., Universidad Nacional Autónoma de México, 2007, pp. 375-399. Discrepo allí de otras propuestas anteriores. El teatro de Peralta Barnuevo fue publicado en Obras dramáticas con un apéndice de poemas inéditos, introducción, edición y notas de Irving A. Leonard, Santiago de Chile, Imprenta Universitaria, 1937. Remito en las citas a la numeración de versos del entremés dada allí, aunque establezco mis propios criterios de edición.

3. José de la Riva-Agüero destacó la presencia de elementos regionales en algunas piezas breves de Peralta y advirtió que estas obras prefiguran el teatro costumbrista peruano de la primera mitad del siglo XIX («Pedro de Peralta y las influencias francesas en sus obras», en Estudios de literatura peruana: del Inca Garcilaso a Eguren, Lima, Pontificia Universidad Católica del Perú, 1962, vid. pp. 192-193. José Juan Arrom llamó también la atención sobre «el sabor criollo de algunas de sus expresiones» (El teatro hispanoamericano en la época colonial, La Habana, Anuario Bibliográfico Cubano, 1956, p. 147). 
Para avanzar en este objetivo, centraré mi atención en el entremés que Peralta compuso para intercalarse entre las jornadas de La Rodoguna, adaptación de la tragedia Rodogune de Corneille. Este es el único caso que conocemos de un entremés escrito por Peralta, pues el resto de su producción de teatro cómico breve está compuesto por dos bailes y dos fines de fiesta, procedentes de los otros dos festejos teatrales del autor. Mi intención es mostrar cómo, más allá de la simple observación de nombres y vocablos que dan un aparente aspecto "costumbrista» al texto, una adecuada labor de anotación e interpretación filológica permite reconstruir y revelar la peculiar perspectiva criolla que Peralta desarrolla en esta pieza.

Al enfatizar el carácter criollo, aludo fundamentalmente a tres premisas que definen la escritura de una obra como esta. La primera se refiere a su evidente adscripción a la tradición teatral espańola y al particular uso que el autor hace de ella. Mediante el entremés -la forma más elaborada y de mayor proyección dentro del teatro cómico breve-, Peralta se confronta con la tradición recibida del teatro hispano; la incorpora y, al mismo tiempo, la amolda a sus propios objetivos estéticos e ideológicos. Ello es característico de quien escribe, a la vez, como partícipe en los valores del Imperio y como exponente de una posición diferenciada desde los virreinatos americanos. De este modo, la pieza cómica breve puede resultar, en cuanto a su estructura argumental básica, bastante convencional -un conjunto de personajes actúa para lograr la satisfacción de su deseo o la ejecución de una burla, tal como ocurre habitualmente en las obrillas de este género-; pero, el mundo representado resulta novedoso, si se mide desde la perspectiva de los referentes convencionales del género.

La segunda premisa remite a los objetivos de esa representación. Peralta emplea los géneros cómicos del teatro breve no solo para incorporar, a través del léxico y los personajes, formas estilizadas de representación de la vida doméstica en la Lima de las primeras décadas del siglo XVIII, sino fundamentalmente para aludir a un mundo social en que interactúan distintos grupos diferenciados por su origen y sus expectativas dentro del orden colonial. En tal sentido, en su brevedad, el entremés construye, mediante los códigos de la teatralidad, un microcosmos de la sociedad colonial limeña.

El tercer principio corresponde al circuito para el que fue concebida la piececilla y al uso de este contexto para la expresión de posiciones criollas. Está destinada originalmente a ser representada en el Palacio virreinal como parte de un espectáculo que sirve a una celebración imperial. En tal sentido, la obra mayor en la cual se inserta ( La Rodoguna) contribuye a la solemnidad de la fiesta mediante la afirmación de los valores estéticos asociados al poder del monarca: para celebrar a Felipe V, el príncipe francés convertido en rey de España, Peralta retoma una de las piezas fundamentales del corpus teatral de la corte francesa, de donde procede el monarca (la tragedia Rodogune de Corneille), y la adapta a la modalidad del teatro español. El drama sigue la misma transformación que la carrera política del soberano: de Francia a España. En medio de este particular 
experimento estético-político, inserta un entremés de explícitos contenidos criollos, de modo que la obra mayor, con su claro contenido imperial acorde a las circunstancias de la nueva dinastía reinante en España (la de los Borbones), sirve de marco para la recepción de la piececilla criolla ${ }^{4}$.

Desde esta perspectiva, examinaré el modo como, a través de los 218 versos que componen el entremés para La Rodoguna, se construye una representación de los personajes como individuos diferenciados por sus orígenes, sus costumbre o sus actividades, en alusión permanente al mundo social y cultural limeño propio del momento en que la obra fue escrita. El argumento del entremés es simple, pero su interés está en el modo como se negocian las diversas expectativas amorosas entre cuatro muchachas limeñas y sus correspondientes pretendientes: un sacristán que sirve de maestro de canto, un poeta que actúa como maestro de leer, un maestro de danza y un mercachifle. Al margen de las cuatro parejas, actúa Lorenzo, el padre de las muchachas, caracterizado como villano en la lista de personajes y que se expresa a través de un lenguaje rústico característico de la tradición dramática española. Él espía a los amantes, evidencia con sus comentarios sus encubiertos avances eróticos, y está a punto de arruinarlos cuando su presencia es descubierta. Sin embargo, rápidamente se deja convencer por una oportuna merienda servida a costa de los pretendientes. De este modo, se cancela toda censura moral y el posible burlado (el padre en cuya casa puede entrar la deshonra a través de sus hijas), se convierte en un tolerante colaborador a cambio de unos cuantos beneficios. El entremés puede cerrarse así en gozo compartido y alegre danza.

Tanto la onomástica como la expresión verbal de los personajes establecen oposiciones muy claras. La ambientación limeña de la pieza está marcada, en primer lugar, por los nombres de las muchachas que son llamadas por los hipocorísticos que eran entonces habituales en la ciudad: Mariquita por María (este de uso panhispánico), Chepita por Josefa, Panchita por Francisca y Chanita por Juana. Estos sobrenombres continuaban vigentes en el Perú por lo menos hasta mediados del siglo XX, antes que un marcado cambio en la onomástica peruana los fuera relegando paulatinamente. En todos los casos, aparece en los nombres femeninos el típico diminutivo afectivo y de cortesía, aun vigente en

4. En mi artículo citado he estudiado las condiciones particulares que explican la elaboración de esta pieza teatral de Peralta. La obra fue escrita tras un período de crisis en la escena limeña (situación que es aludida y alegóricamente dramatizada en la loa), el cual ocasionó que incluso dejaran de hacerse los festejos teatrales por las celebraciones imperiales en la corte virreinal. La representación de La Rodoguna en 1727 marcó el retorno de las representaciones en Palacio y fue además la primera tras el inicio del segundo reinado de Felipe V, luego del breve período de Luis I. Peralta aprovecha estas circunstancias y elabora una obra que recuerda en su fuente (el texto de Corneille) el origen del poder del monarca, pero simultáneamente plantea, sobre todo a través del marco de la loa, la expectativa de que el nuevo reinado de Felipe $V$ marque el inicio de un ciclo en que se satisfagan las expectativas criollas. Sobre las transformaciones que efectúa Peralta respecto del texto de Corneille, véase I. Leonard, «An Early Peruvian Adaptation of Corneille’s Rodogune», Hispanic Review, vol. 5, nº. 2, Apr., 1937, pp. 172-176. 
el habla americana y particularmente peruana, que, en el siglo XIX daba pie a que Juan de Arona recordara, a propósito del apelativo Chepita, que no usarlo en diminutivo sería "prueba de mal gusto y hasta de descortesía"s.

Es justamente en el habla de las muchachas donde aparecen los vocablos de carácter americano o específicamente local. Mariquita, por ejemplo, se refiere a su amante llamándolo chino lindo (una expresión que luego comentaré). Ella misma llama taita a su padre (v. 215), una palabra que, si bien es de origen latino (tata) y en España era forma familiar e infantil para designar al progenitor (y como tal ya está testimoniada en el vocabulario de Nebrija de $1495)^{6}$, en el Perú perdió este ámbito exclusivo de uso y se convirtió en forma de tratamiento usada también por los mayores, como en el texto de Peralta, e incluso extendió su campo de designación ya no solo al padre, sino a toda figura masculina de respeto o autoridad. Su uso arraigó tanto que se incorporó al quechua y hoy está tan integrado en esta lengua que muchos hablantes se sorprenden de descubrir su origen hispano. De otro lado, el término tamal -en principio palabra de origen nahuatl (tamatli), pero difundida por toda América para designar alguna variedad de empanada de maíz envuelta en hojas y con relleno de alguna carne- aparece utilizado por las hijas en el sentido figurado de «lío, trampa», que tardíamente Alemany y Bolufer reconoce como característico del Perú y de Cuba. Así, al percatarse de la presencia del padre, las hijas se preguntan preocupadas: «¿Qué haremos si de esta gira / ha desenvuelto el tamal?» (vv. 166-167) ${ }^{7}$.

En sus nombres y en su léxico las tres hijas hacen notar su origen y su pertenencia a la ciudad de Lima. Son ellas asimismo las que claramente dominan la escena y controlan la trama. Saben cuánto ceder y cuánto resistir a los avances de sus amantes e incluso cómo dominar la oposición de su padre. Por supuesto, la figura de la mujer pícara que se burla y obtiene beneficios de presuntuosos galanes estaba bien asentada en la tradición del entremés. Como parte de la inversión del mundo social que es característica de este género teatral, no es raro que la mujer domeñe y engañe al varón (la esposa al esposo,

5. J. de Arona (seud. de Pedro Paz Soldán y Unanue), Diccionario de peruanismos, t. X de la Biblioteca de Cultura Peruana, París, Desclée de Brouwer, 1938, p. 164; sobre Chana y Pancha, pp. 161 y 302. Enrique Carrión Ordóńez estudia el origen y el uso de algunos hipocorísticos peruanos en el documentado vocabulario incluido en su libro La lengua en un texto de la Ilustración. Edición y estudio filológico de la Noticia de Arequipa de Antonio Pereira y Ruiz, Lima: Pontificia Universidad Católica del Perú, 1983 (sobre Chepe, pp. 354-356, y sobre Pancha, 361362). Sobre el uso más común del hipocorístico Mariquita, bastará recordar que figura en varios entremeses españoles, tales como La hija del doctor, de Francisco de Avellaneda, y da título a uno de Agustín Moreto, el Entremés de Mariquita.

6. A. de Nebrija, Vocabulario español latino, Salamanca, 1495.

7. José Alemany y Bolufer, Diccionario de la Lengua Española, Barcelona, Ramón Sopena, 1917. Gira, en principio «el banquete espléndido que se hace entre amigos, con regocijo, bulla y chacota», tiene aquí el sentido por extensión de "cualquier bulla o regocijo entre muchos» (Real Academia Española, Diccionario de Autoridades, Madrid, 1734). 
la buscona al caballero). Sin embargo, dentro de esa fórmula, es significativo el énfasis puesto en la piececilla de Peralta por definir la procedencia de los personajes: las ingeniosas jóvenes criollas frente al rústico padre español.

El padre de las muchachas, en efecto, se llama Lorenzo, un nombre habitual en el teatro español para la designación de personajes rústicos cómicos ${ }^{8}$, y está caracterizado idiomáticamente por el uso de algunos rasgos característicos del «sayagués», la lengua literaria inspirada en el dialecto leonés de la comarca de Sayago, que en el teatro español sirvió desde el siglo XVI (con Juan del Encina y Lucas Fernández) para representar el habla de rústicos y labradores, muchas veces caracterizados como simples o bobos. Como es bien sabido, esta lengua fue ricamente empleada en el teatro español del siglo XVII (aunque cada vez más como una forma convencional desligada de su entorno dialectal original) y continuó vigente en el siglo XVIII en un autor como Diego de Torres Villarroel (1693-1770), por la misma época en que Peralta escribía su entremés. En tal sentido, el personaje de Lorenzo es el vínculo más evidente que establece Peralta con la tradición del entremés español (en una obra en la que, como vemos, abundan los elementos novedosos y locales).

Peralta despliega generosamente algunos de los rasgos más característicos del sayagués para caracterizar idiomáticamente a su personaje. Estos son los más saltantes: a) palatalización de la $l$ latina, sobre todo en posición inicial, aunque también en interior de palabra (lla, lle, lles, llo, adelantalla, desvella, llindo, habellidá-por habilidad-, regallos, lleer, lletra, mozuella, muchachuella); b) alternancia entre formas diptongadas y monoptongadas (pus por pues); c) rotacismo en grupo consonántico (brando por blando); d) alternancia entre la pérdida y la conservación de $-d$ final, procedente de la $-t$ - intervocálica latina (caridá, habellidá y necesidá alternan con crueldad y mitad); e) metátesis de la consonante vibrante (protento por portento); f) uso del sufijo -ura, en la palabra enseñadura (por enseñanza), característico de la lengua española en la época temprana y que aparece, por ejemplo, tal como observó John Lihani, en los textos de Lucas Fernández en palabras como tristura y holgura, que alternan con las formas tristeza y holganza $a^{9}$ g) aspiración inicial, representada por $h$, en palabras que no se corresponden con la $f$-inicial latina, como es más habitual, sino con la $b$-: hueno por bueno, huen por buen ${ }^{10}$; h) uso de vustedes, derivado de vuestras mercedes y antecedente de ustedes, formas que, tal como señala Rafael

8. Véase María José Martínez López, El entremés: radiografía de un género, Toulouse, Presses Universitaires du Mirail, Anejos de Criticón, 9, 1997, p. 143.

9. John Lihani, El lenguaje de Lucas Fernández. Estudio del dialecto sayagués, Bogotá, Instituto Caro y Cuervo, 1973, p. 205.

10. Lihani (op. cit., pp. 147-148) explica que esta sustitución se debía al hecho de que, en la zona vasca durante la etapa temprana de la colonización romana, se trocaba la $f$-inicial latina tanto por la aspiración como por $p$ - o $b$-, como consecuencia de lo cual la aspiración podía proyectarse también hacia las palabras que originalmente se iniciaban con estas dos consonantes. 
Lapesa, en el siglo XVII eran "propias de criados y bravucones»" ${ }^{11}$, y que en el teatro de la época aparecen habitualmente entre los personajes de las piezas cómicas breves o en boca de criados y graciosos.

Junto a esta detallada caracterización lingüística del personaje aparecen también en él los rasgos que lo definen como el típico rústico simple del teatro hispano de los siglos XVI y XVII, sobre todo por su fácil proclividad a satisfacer su apetito, aun a costa de sacrificar la honra familiar. En tal sentido, su presencia en el entremés de Peralta explicita en especial el vínculo con la tradición del modelo teatral español. Al mismo tiempo, sin embargo, su radical expresión lingüística crea un marcado contraste con sus hijas, quienes se manifiestan en un nuevo lenguaje cómico transido de coloquialismos locales.

A diferencia de las muchachas y su padre, los cuatro pretendientes carecen de un nombre propio y son identificados por su ocupación. Al menos dos de ellos, el Sacristán y el Poeta, podrían reconocerse como personajes característicos del teatro cómico breve, pero aquí subordinan sus rasgos más típicos a la ocupación particular que desempeñan en el hogar de Lorenzo: la de maestros de sus hijas, actividad a la que también se suma el maestro de danza. El mercachifle, en cambio, destaca particularmente en el contexto de la pieza por el hecho de que, además, es el único que tiene algo que perder (sus mercancías y su dinero) y que, por tanto, se asemeja en ello un tanto a Lorenzo, cuya honra familiar está en juego. Ahora bien, la manera como cada uno de los cuatro pretendientes es presentado hace del hogar de Lorenzo un espacio en que la composición del mundo colonial se trasluce a través del espejo deformante de la comicidad.

El entremés se inicia con la salida del Sacristán que entona sus lamentos de amor dirigidos a Mariquita. Su canto vence finalmente a la coqueta muchacha, quien lo acepta con estas palabras:

$\begin{array}{ll}\text { MARIQUITA canta: } & \text { Fuerza es que conquistes } \\ & \text { el pecho que rindo } \\ & \text { al aire, a los chistes } \\ & \text { que tiene tu voz. } \\ & \text { Si así, chino lindo, } \\ & \text { me dices las tristes, } \\ & \text { el tuáutem del Pindo } \\ & \text { no encanta mejor (vv. 9-16). }\end{array}$

Estos ocho versos exigen diversa anotación. Reparemos, en primer lugar, en el apelativo chino lindo con el que Mariquita se dirige al Sacristán. El uso de chino como expresión afectuosa, sobre todo entre enamorados, está documentado en diccionarios y vocabularios de americanismos de los siglos XIX y XX correspondientes a zonas tan distantes como Cuba, Colombia, Chile, Venezuela y Perú. Con el sentido afectuoso y encomiástico, la expresión chino lindo llega hasta textos de la literatura cubana y argentina del siglo XX. Este pasaje de

11. Rafael Lapesa, Historia de la lengua, Madrid, Gredos, 1981, p. 392. 
Peralta es la documentación más antigua que conozco de este uso afectivo. El americanismo chino es aquí la forma masculinizada (adaptada a la morfología castellana) del quechuismo china ('hembra, sirvienta', forma ya recogida en el Vocabulario de González Olguín, 1608), y su uso se encuentra en tempranos textos coloniales andinos con su sentido original de 'sirvienta indígena'. De allí, el término, con su correspondiente masculino, pasó a designar 'indio' en general en la zona sur andina, y este uso se recoge en varios diccionarios del siglo XIX y de inicios del XX. Por ejemplo, Vicente Salvá en 1846 define esta acepción de chino como «el indígena del Perú, cuyos ascendientes han nacido en él» ${ }^{12}$. Sin embargo, al menos desde la segunda mitad del siglo XVIII, tal como atestiguan las leyendas incluidas en algunos cuadros de castas, chino y china se aplicaron para referirse a diversas formas de mestizaje ${ }^{13}$. Las categorías son, sin embargo, variables y esa indeterminación pasa a los diccionarios del siglo XIX, deudores de una práctica que venía del siglo anterior. De otro lado, el uso de términos étnicos que pueden adquirir valor afectivo (y también despectivo) es característico hasta hoy del habla hispanoamericana y, en tales casos, su sentido propiamente étnico es más impreciso, como ocurre en este pasaje de Peralta.

Sin embargo, otro indicio en el mismo pasaje, nos lleva a pensar que el chino lindo del entremés de Peralta no es solamente un enamorado, sino también un mestizo con algo de sangre indígena, pues la mención a su canto como «tristes» podría ser una alusión a los yaravíes, pues, tal como recuerda Juan de Arona, triste es «el nombre español del yaravi, por lo que se dice tocar o cantar un triste $\rangle^{14}$, si bien las formas que conozco le atribuyen siempre género masculino a esta acepción. El uso del término se extendía para entonces hasta Argentina y Venezuela ${ }^{15}$. En su Descripción e historia del Paraguay y el Río de la Plata (concluida en 1806, pero publicada póstumamente en 1847), Félix de Azara, describiendo las costumbres de los españoles y criollos del campo, afirmaba que

en cada pulpería hay una guitarra, y el que la toca bebe a costa ajena. Cantan Yarabís o Tristes que son cantares inventados en el Perú, los más monótonos y siempre tristes, tratando de ingratitudes de amor, y de gentes que lloran desdichas por los desiertos ${ }^{16}$.

12. Vicente Salvá, Nuevo diccionario de la lengua castellana que comprende la última edición integra, muy rectificada y mejorada del publicado por la Academia Española, y unas veinte y seis mil voces, acepciones, frases y locuciones, entre ellas muchas americanas, París, Librería de don Vicente Salvá, 1846.

13. Para el caso de los cuadros de castas relativos a la Nueva España, de donde se ha conservado el mayor número de testimonios de estas series pictóricas, puede verse Efraín Castro Morales, "Los cuadros de castas de la Nueva España», Jahrbuch für Geschichte von Staat, Wirstchaft, und Gesellschaft Lateinamerikas, 20, Köln, Boëhlau, Verlag, 1983, pp. 671-690. Referencias al uso de chino en estas clasificaciones de castas, en pp. 4 y 7.

14.Op. cit., p. 488.

15. Ibid.

16. Féliz de Azara, Descripción e historia del Paraguay y el Río de la Plata, Madrid, Imprenta de Sánchiz, 1847, t. I, p. 309. 
Por su parte, el Mercurio peruano en 1791 comenta los efectos que el yaraví produce en quien lo escucha. Su descripción cuadra bien con la situación dramática de queja de enamorado, que, en forma irónica, aquí presenta Peralta:

El Yaraví de cualesquiera suerte que se oiga, suspende, eleva y arrebata la atención más distraída, sin que nadie se pueda retraer de su poderoso atractivo. ¿A quién no se le exasperan las heridas del amor, cuando oye una glosa cantada al propósito del mal de que adolece? ${ }^{17}$

Si se acepta la identificación del Sacristán con un cantor que entona ese canto característico de la cultura mestiza virreinal, la comparación con «el tuáutem del Pindo» adquiere un sentido de encomio sobre esta cultura, pues el tuáutem es, según define el Diccionario de Autoridades, «el sujeto que se tiene por principal y necesario para alguna cosa o la cosa misma que se considera precisa» y, por tanto, «el tuáutem del Pindo» (la montańa dedicada en la Antigüedad a Apolo y las Musas), al que con su canto supera el Sacristán, no es otro que el mismo Apolo.

Menos particular resulta la figura del Poeta, más acorde con la tradicional caracterización del versificador petulante que se muestra en las palabras con que corteja a su amante:

\author{
Chepita soberana, \\ chula, afrenta de Venus y Dïana, \\ dueño eres bello del mayor poeta, \\ con quien Apolo fue numen de teta. \\ Y así, que seas tú, no es cosa extraña, \\ Clicie chusca, Calíope picaña (vv. 21-26).
}

Como es de esperar, el Poeta se sirve del paradigma mitológico para la representación de la amada, pero, como parte del universo burlesco del entremés, lo banaliza o lo degrada. Apolo es apenas «numen de teta», comparado con el presuntuoso Poeta, en frase que obviamente propone un juego idiomático con la expresión niño de teta que «se dice del que es inferior a otro con mucha diferencia en alguna de sus cualidades» (Aut.). Chepita se convierte, a su vez, en "Clicie chusca, Calíope picaña». La Clicie de las Metamorfosis que, abandonada por Apolo y celosa de los amores del dios por Leucótoe denuncia a esta ante su padre y ocasiona su muerte y que luego se consume y se transforma en el heliotropo que gira siguiendo al sol, pierde aquí toda su dignidad trágica, pues es tildada de chusca, «la persona que tiene gracia, donaire y cierta libertad para hacer o decir las cosas" (Aut.). Lo mismo ocurre con Calíope, una de las nueve musas, identificada, desde el período alejandrino con la poesía lírica, aquí calificada de picaña (Picaño: «Pícaro, andrajoso, holgazán y de poca vergüenza», $A u t$.). En el juego burlesco que sigue el entremés, el Poeta, que se cree más que Apolo, encuentra su correspondiente amoroso en una amante

17. Mercurio peruano, 22 de diciembre de 1791, p. 287. 
dicharachera (que parodia a la delatora Clicie del mito) y su inspiración en una «antimusa» (una Calíope vuelta pícara). Más allá, sin embargo, de los juegos más o menos convencionales con que Peralta presenta al vanidoso poeta, cabría preguntarse si, en el contexto que va creando el entremés, el poeta, poseedor y administrador de la escritura, no es una graciosa alusión al criollo, el grupo social al que pertenece el propio Peralta y que, para inicios del siglo XVIII, es el principal responsable de la producción textual, incluso de aquella destinada a preservar y consolidar las manifestaciones del poder virreinal.

El Mercachifle, en cambio, es figura central en el entremés en tanto que, a través de su discurso, da indicios relevantes de su procedencia y su lugar en la sociedad colonial. En primer lugar, hay que recordar que el propio término (formado de mercar + chifle) surge en el Perú para designar al vendedor ambulante que iba por las calles ofreciendo su mercancía, la cual llevaba en un atadillo, y que llamaba la atención haciendo sonar un silbato o chifle. El mercachifle fue una figura característica en la Lima del XVIII. Un aspecto clave para entender su posición en ese universo social al que alude el entremés es su condena a la tierra donde ejerce su actividad:

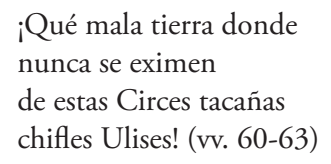

Ello revela que se trata de un peninsular recién llegado y, de ninguna manera, de un criollo, para quien la exaltación de la ciudad nativa hubiera sido lo esperable. Durante el siglo XVIII fue habitual, en efecto, la llegada de españoles peninsulares que se dedicaron al mercadeo y concretamente al comercio ambulatorio. Muchos de ellos experimentaron un rápido ascenso social, en parte por el éxito en los negocios, pero también por las alianzas matrimoniales con ricas herederas criollas, lo cual motivaba a veces la envidia y el odio en la sociedad limeńa. Esta situación, que de alguna manera aquí parodia Peralta al hacer que toda expectativa de fortuna por parte del Mercachifle sea arruinada por la ambición de Panchita, es descrita así por Jorge Juan en sus Noticias secretas de América:

Después que se casan, entran a ser regidores, e inmediatamente obtienen los empleos de alcaldes ordinarios, de modo que, en el discurso de diez u once años, se halla gobernando una ciudad de aquéllas, y hecho señor de los aplausos y de las primeras estimaciones un hombre que antes pregonaba por las calles, con un atadillo, las menudas mercancías y bujerías que otro le dio fiadas para que empezase a trabajar ${ }^{18}$.

El origen foráneo del mercachifle se confirma con la alusión en los versos siguientes al mito del viajero Ulises que recala en la isla de Circe y tiene que afrontar los sortilegios de esta, el cual sirve a Peralta para presentar al español recién llegado que se confronta con los encantos de la joven criolla. Solo

18. Jorge Juan, Noticias secretas de América, ed. de Luis J. Ramos Gómez, Madrid: CSIC, 1985 , pp. 336. 
que, en este caso, el mito es degradado por la calificación de los personajes. La hechicera del mito da lugar aquí a "Circes tacañas», donde tacaño guarda el sentido original de «astuto, pícaro, bellaco, y que engaña con sus ardides y embustes» (Aut.). De otro lado, mediante una creativa aposición, el héroe griego se convierte en «Ulises chifles». Peralta sigue aquí un procedimiento semejante al que dio origen a la palabra «mercachifle». Así, en un solo sintagma queda aludido el origen extranjero (por Ulises) y el oficio de mercader (por el uso del chifle) del personaje.

La figura del Maestro de danza, por su parte, sirve para presentar la temprana aparición de danzas de moda de influencia francesa en la sociedad limeña. Lima recibe el impacto del afrancesamiento a partir del cambio dinástico, pero sobre todo a raíz de la llegada a Lima como virrey del Perú de Manuel de Oms y Santa Pau, marqués de Castell dos Rius, noble catalán que venía de ejercer el cargo de embajador de España en la corte de Luis XIV durante los años en que se produjo la sucesión borbónica al trono español. Cuando el Maestro anuncia, por tanto, que «y ahora al uso es preciso / poner en baile el amar» (vv. 80-81) se refiere propiamente a la necesidad de expresar el amor de acuerdo con las nuevas modas del baile.

Los términos de la danza servirán así para expresar metafóricamente las expectativas amorosas del maestro:

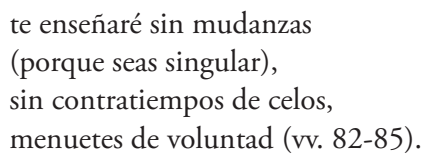

donde mudanza remite tanto a «cierto número de movimientos, que se hace en los bailes y danzas, arreglado al tañido de los instrumentos» (Aut.), como a «la inconstancia o variedad de los afectos y dictámenes» (ibid.); mientras que contratiempo «en el baile, se dice cuando habiendo de poner en el suelo un pie que está en el aire, se da, antes de verificarlo, un salto sobre el otro pie», pero "también infortunio o calamidad que sobreviene» ${ }^{19}$.

Chanita seguirá el modelo de expresión lingüística propuesto por su maestro:

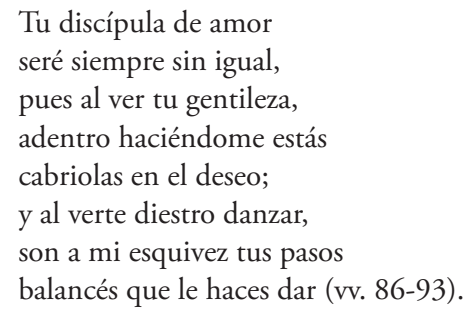

19. Gaspar y Roig, Diccionario enciclopédico de la lengua española, Madrid, Imprenta y Librería de Gaspar Roig, 1853. 
Cabriolas es el «brinco que dan los que saben danzar, meneando y cruzando los pies en el aire» (Aut.) y balancés, «un paso que se hace en el mismo lugar como la pirueta; mas en presencia por lo común, aunque también se puede hacer dando vueltas ${ }^{20}$. Ya sea porque el balancé se hace en un mismo sitio, sin avanzar, o porque se puede hacer girando (siempre en el mismo lugar), la idea es que Chanita se detiene entusiasta ante los avances (los pasos) del Maestro.

Mediante estos juegos verbales, el entremés de Peralta ofrece una rica documentación sobre el impacto de las danzas francesas en la sociedad limeña del siglo XVIII (el minuet, el passepied -pasapiés en Peralta, llamado también paspiés-, y la bourrée -burea en Peralta, siguiendo la mediación italiana en la adopción de la palabra-, así como de los pasos correspondientes (cabriolas, balancés). La llegada de los nuevos usos de danzas desde principios del siglo XVIII generó en Lima la proliferación de maestros de danzar. Incluso, según comenta Juan Carlos Estenssoro, se hizo habitual que muchos de ellos fueran negros, hasta que, a fines del siglo XVIII, estos fueron prohibidos, lo que dio lugar a la creación de academias particulares de danzas, dirigidas en varios casos por profesores extranjeros ${ }^{21}$. No obstante, no existe en el texto del entremés ningún rasgo lingüístico que permita confirmar esta asociación entre el maestro de danza y la importante población negra de la ciudad. Por tanto, aunque ello completaría el universo étnico y social de la ciudad representado en el entremés (mestizos, criollos, españoles peninsulares, negros), más parece que la intención fuera mostrar la dinámica de una sociedad donde coexisten las tradiciones nativas o mestizas (como el yaraví) con el impacto de nuevas modas difundidas a través de la cultura cortesana.

Los avances eróticos de los pretendientes son declarados y censurados en los comentarios en aparte que, desde el bastidor, hace Lorenzo. En estas intervenciones aflora el lado más carnavalesco del lenguaje del entremés, con sus juegos polisémicos que abundan en lo obsceno. Las escenas en que los pretendientes se relacionan con las muchachas habían permitido que el léxico propio de cada actividad (el canto, la escritura, la danza, el comercio) adquiriera connotaciones amatorias. Las intervenciones de Lorenzo degradan por completo ese procedimiento, que se ha mantenido en un estilo cómico cortesano, y revelan abiertamente las verdaderas apetencias eróticas de los pretendientes. A partir de su aparición, cada frase dicha por los otros personajes relativa a su actividad como maestros o como vendedor se entenderá paralelamente como una descarnada metáfora sexual ${ }^{22}$.

20. Enciclopedia metódica. Artes académicos, traducidos del francés al castellano, a saber, el Arte de la equitación por don Baltasar de Irurzun; y el del Baile, de Esgrima y de Nadar, por don Gregorio Sanz, en Madrid, en la Imprenta de Sancha. 1791.

21. J. C. Estenssoro, Música y sociedad coloniales. Lima 1680-1830, Lima, Editorial Colmillo Blanco, 1989, pp. 67-68.

22. Por ejemplo, al ver al Sacristán abrazar a Mariquita, comenta Lorenzo: «Qué hábil que es lla muchachuella! / ¡Qué diestro es el sacristán, / pus cuando empieza por brando, / por 
Los comentarios de Lorenzo aportan un tono burlesco y desenfadado a la comicidad del entremés; pero definen también una característica fundamental de esta pieza: más que una burla consumada como acción, lo que se ofrece es una simulación de la burla a través del lenguaje y finalmente una solución que la cancela. De un lado, la burla erótica contra el honor de la autoridad patriarcal (en este caso, no el esposo, sino el padre) no trasciende el plano de las crudas metáforas obscenas que el propio Lorenzo imagina. Paralelamente ni las muchachas ni los pretendientes pueden considerarse burlados. Las primeras mantienen y controlan el juego erótico hasta donde este les permite obtener beneficios de placer y entretenimiento o incluso económicos. Por su parte, los pretendientes deben sufrir el despecho (o incluso el despojo, en el caso del Mercachifle) de sus amadas, pero finalmente obtienen las complacientes caricias de estas. Esto permite que posibles burladores y burlados establezcan finalmente pactos y satisfagan conjuntamente sus deseos en el consumo de una suculenta merienda.

Es posible ver en esta solución, la manera particular como Peralta concebía la sociedad colonial criolla: como un espacio sujeto a una dinámica de intercambios, transformaciones y negociaciones, donde bajo una simulación de acatamiento, diversos grupos actuaban según sus intereses. Al incluir este particular entremés en un festejo teatral cortesano, Peralta otorgaba también un lugar a ese universo en el marco de la celebración imperial. Esa intención solo se nos revela a través de una adecuada anotación que explicite las alusiones a la tradición teatral hispana, los ingeniosos juegos polisémicos de la pieza o los referentes sociales y culturales propios del momento en que Peralta escribió su texto.

natura ha de acabar!» (vv. 102-105). De un lado, se reconocían tres propiedades de la Música: becuadrado, natura y blando (o bemol), de las que se derivaban los seis tipos de voces y sobre las que se asentaban las tres claves que se empleaban en la notación. La «destreza» musical del Sacristán estaría, por tanto, en saber pasar de bemol o blando (brando en la típica pronunciación del personaje) a natura. Sin embargo, en su sentido erótico, blando y natura aluden a las partes del cuerpo de Mariquita. Blando refiere probablemente a las carnes de la muchacha que abraza el Sacristán, o también a su disposición sensual, pues el término significa asimismo «voluptuoso, lúbrico, sensual, lleno de molicie, dado a la molicie; hablando de cosas y de personas» (Ramón J. Domínguez, Diccionario nacional o gran diccionario clásico de la lengua española, Madrid, París, Establecimiento de Mellado, 1853); mientras que natura (o su equivalente naturaleza) «se llama también el sexo, especialmente en las hembras» (Aut.s. v. naturaleza). 
